\title{
A HIGH VOLTAGE GAIN RECTIFIER-FED TWO-STAGE STEP-UP DC-DC CONVERTER WITH PI CONTROLLER
}

\author{
Dr. D. Murali \\ Associate Professor, Department of EEE \\ Government College of Engineering, Salem, TN, India
}

\begin{abstract}
This paper presents the analysis and simulation of a closed-loop configuration of a non-isolated two-stage DC-DC boost converter operating in continuous conduction mode (CCM) with fixed switching frequency. The proposed converter shows improved voltage conversion ratio compared to the conventional boost converter. The proposed converter is fed by an uncontrolled diode bridge rectifier for which the input AC voltage is $80 \mathrm{~V}$ (rms). The design of the two-stage converter is such that the input AC voltage of $80 \mathrm{~V}$ (rms) is stepped up to around $800 \mathrm{~V}$ (DC) at the end of the second stage. The closed-loop configuration with a simple PI (Proportional+Integral) controller for the proposed converter is simulated in Matlab/Simulink platform. The closed-loop implementation maintains higher constant output voltage profile despite changes in input voltage and significantly reduces overshoot when compared to openloop configuration. A prototype model of the converter has been developed to validate its performance.
\end{abstract}

Keywords - Boost converter, Closed-loop implementation, Continuous Conduction Mode, Matlab/Simulink, Openloop configuration, PI controller

\section{INTRODUCTION}

Now a days, a DC-DC converter consisting of two stages is becoming popular as the use of first stage eliminates the second harmonic voltage effect that is reflected at the output because of single phase AC mains input [1]-[2]. The first stage converter can be a non-isolated DC-DC converter and the second stage may be an isolated or non-isolated DC-DC converter. To reduce the complexity, cost and space, only a single output is sensed and regulated by feedback control. Generally, in the front end, a diode bridge is used to convert $\mathrm{AC}$ mains voltage to unregulated DC voltage. In the present work, to improve and regulate the DC output voltage, two stages of DC-DC conversion are used. The two-stage scheme is the most commonly used approach [3]. In this approach, an active power factor correction stage is employed as the frontend to force the line current to track the line voltage. Additionally, the power factor correction stage establishes a loosely regulated high voltage DC at its output, which serves

\author{
S. Annapurani \\ PG Scholar, Department of EEE \\ Government College of Engineering, Salem, TN, India
}

as the input voltage to a conventional DC/DC stage with a tightly regulated output voltage. The two-stage scheme is a cost-effective approach in high power applications.

The analysis of the major component ratings of the continuous conduction mode (CCM) single-stage power factor correction (PFC) and the CCM boost two-stage PFC converters is given in [4]. A systematic digital control method is proposed by some authors for the two-stage DC-DC converter and the experimental results are presented to illustrate the design procedure [5]. A two-stage DC/DC converter with wide input range for electric vehicles is presented in [6], where the conversion efficiency of the two-stage converter is evaluated with both theoretical analysis and experiment. A comprehensive review of voltage-boosting techniques, topologies, and applications of step-up DC-DC converters is presented by some authors [7]. Advanced topologies of highvoltage-gain DC-DC boost converters are suggested by some authors for renewable energy applications [8]. A single switch AC/DC converter with extended voltage conversion range is proposed for SMPS applications in [9].

The input-parallel-output-series (IPOS) architectures for the combined converters to achieve high voltage gain are proposed by some authors in [10]. These architectures are responsible for the increase of cost and circuit size with the reduction of reliability. The power quality improvement in switched mode power supplies using two-stage DC-DC converter is analyzed in [11]. The analysis of soft-switched CCM boost converters with high voltage gain for high-power applications is presented in [12]-[14] where the voltage conversion ratio is almost doubled compared to the conventional boost converter.

In this paper, the analysis of a two-stage DC-DC converter with high voltage conversion ratio is proposed. The first stage converts a low level DC voltage to a high level DC voltage using a boost inductor and a boost switch [15]. The output of the first stage is given as input to the second stage called CCM boost converter which is capable of producing still increased DC output voltage across a resistive load.

The rest of the research work presented in this paper is organized in the following sequence. The proposed converter configuration and its operation have been presented in section II. The simulation results and discussions are given in section 


\section{International Journal of Engineering Applied Sciences and Technology, 2019 \\ Vol. 4, Issue 8, ISSN No. 2455-2143, Pages 160-164 \\ Published Online December 2019 in IJEAST (http://www.ijeast.com)}

III. The prototype model of the converter is explained in section IV. This is followed by the conclusion in the concluding section $\mathrm{V}$.

\section{PROPOSED CONVERTER CONFIGURATION AND OPERATION}

The circuit configuration of the proposed rectifier-fed nonisolated two-stage DC-DC boost converter is shown in Fig.1. The single phase AC supply of $50 \mathrm{~Hz}$ frequency is fed to a diode bridge rectifier which gives an uncontrolled DC voltage. The ripples in the DC voltage are filtered by a capacitor. The filtered DC output is given to a boost power stage which acts as the first stage of DC-DC conversion. The boost power stage consists of a suitably designed boost inductor, a boost rectifier, a boost pre-charge diode, and a boost (MOSFET) switch. The boost stage has the filter inductor on the input side, which provides a smooth continuous input current waveform. The continuous input current is much easier to filter. For the CCM, the full load inductor current ripple is typically designed to be $20-40 \%$ of the average input current. The filter inductor value and its maximum current are determined based on the specified maximum inductor current ripple as shown below [15]:

$$
\begin{aligned}
& L_{b}=\frac{1}{\% \text { Ripple }} \frac{V_{a c \cdot \min }^{2}}{P_{0}}\left(1-\frac{\sqrt{2} V_{a c \cdot \min }}{V_{0}}\right)\left(\frac{1}{f_{s}}\right) \\
& I_{L . \max }=\frac{\sqrt{2} P_{0}}{V_{a c \cdot \min }}\left(1+\frac{\% \text { Ripple }}{2}\right)
\end{aligned}
$$

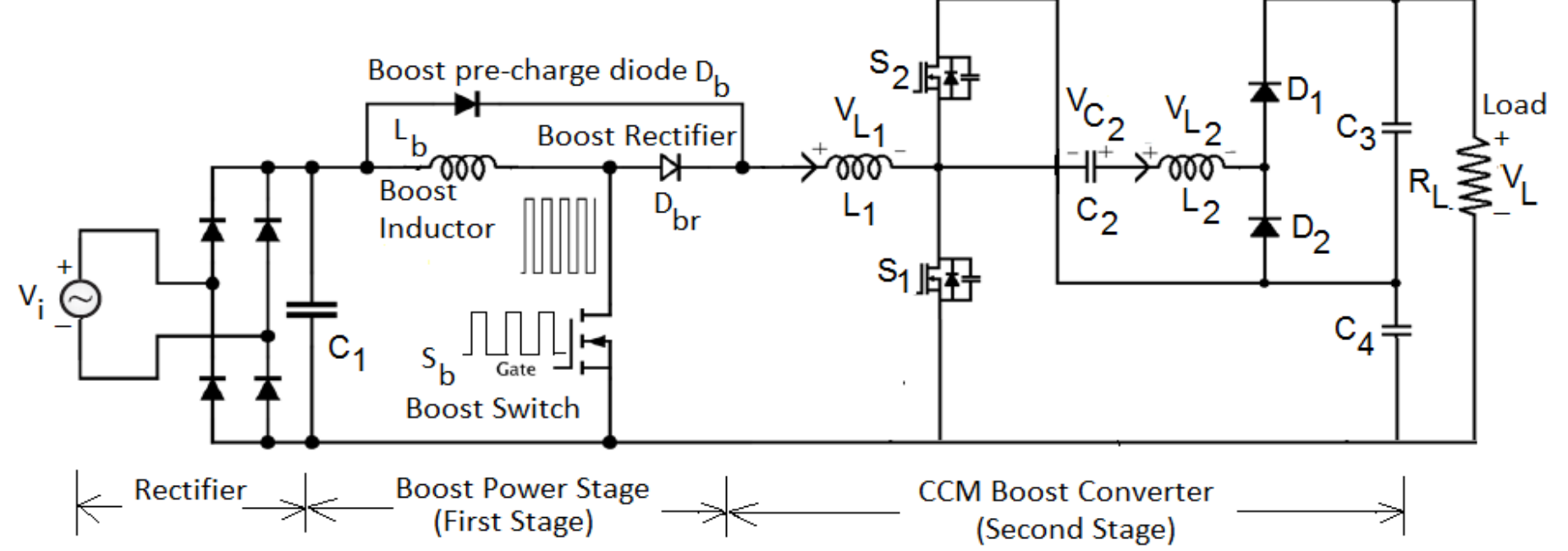

Fig. 1 Circuit configuration of the proposed rectifier-fed non-isolated two-stage DC-DC boost converter

A highly boosted DC voltage is obtained at the output terminals of the first stage. This highly boosted DC voltage from the first stage is given as input to the second stage (CCM boost converter). In order to regulate the DC output voltage, the MOSFET switches $S_{1}$ and $S_{2}$ are operated with asymmetrical complementary switching pattern. When the switch $S_{1}$ is in ON state, the inductor $L_{1}$ stores energy. A group of elements consisting of a capacitor $\mathrm{C}_{1}$, an inductor $\mathrm{L}_{2}$ and two diodes $\mathrm{D}_{1}$ and $\mathrm{D}_{2}$ forms an auxiliary circuit. The auxiliary circuit is used to increase the output voltage by charging the capacitors $C_{2}$ and $C_{3}$ through the diodes $D_{1}$ and $D_{2}$, which also helps turn-on of switches $S_{1}$ and $S_{2}$ under Zero Voltage Switching (ZVS) in Continuous Conduction Mode $(\mathrm{CCM})$. The diodes $\mathrm{D}_{1}$ and $\mathrm{D}_{2}$ are turned off under Zero Current Switching (ZCS). The output voltage across the load is obtained as the sum of the voltages across the capacitors $C_{2}$ and $\mathrm{C}_{3}$ [12].

$V_{0}=V_{C 2}+V_{C 3}$

\section{SimUlation RESUlTS AND Discussion}

The proposed converter model is developed and simulated in Matlab/Simulink platform. The simulation diagram of the proposed two-stage converter is shown in Fig. 2. The proposed rectifier-fed two-stage boost converter is simulated at a switching frequency of $50 \mathrm{kHz}$. The values of circuit components for simulation are selected based on the design considerations and are listed in Table I shown below. Table II lists the specifications of the proposed converter. The proposed converter circuit is simulated using solver 'ode 45' of variable-step type. The Simulink uses a graphical user interface (GUI) for solving process simulations. The gating pulses to the main switches $S_{1}$ and $S_{2}$ are shown in Fig. 3. The duty ratio ' $\mathrm{D}$ ' of the switches is varied between 0.6 and 0.8 . 


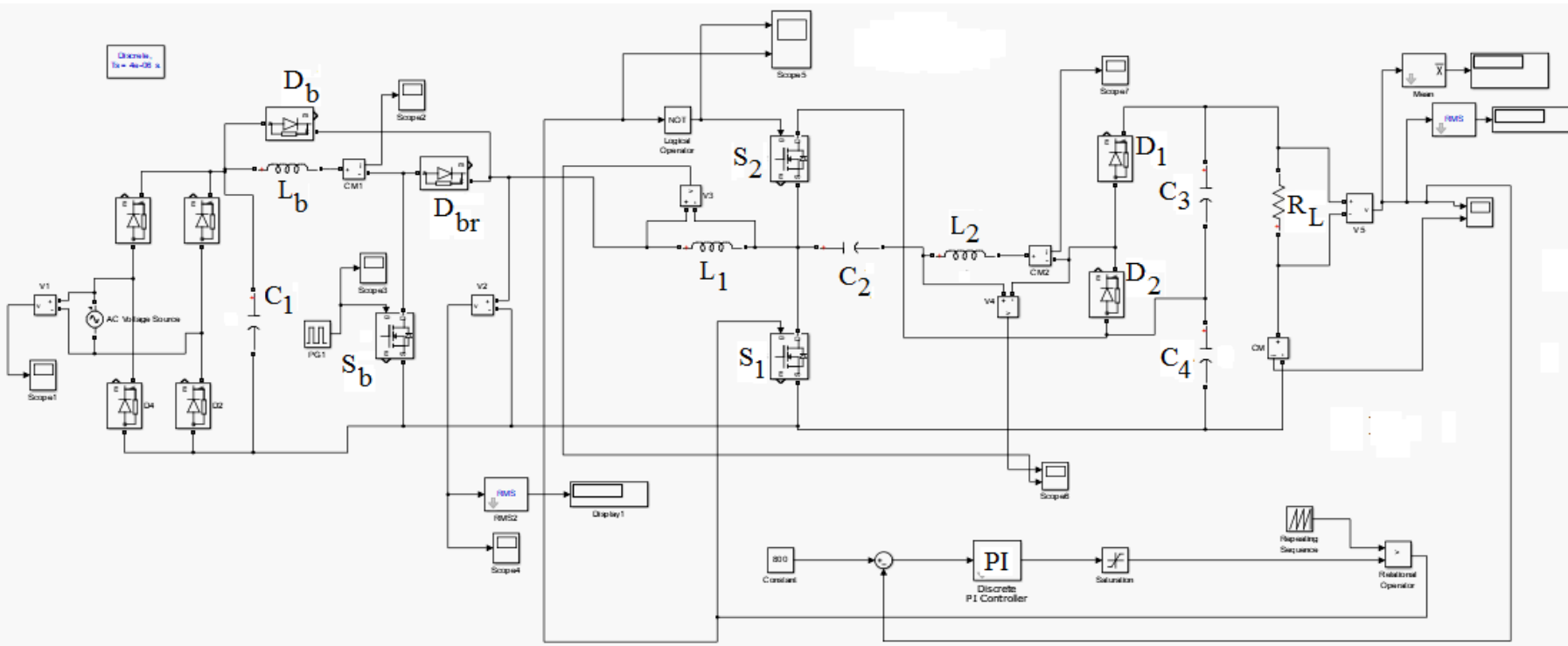

Fig. 2 Simulation diagram of the proposed two-stage DC-DC converter configuration

Table I: Simulation parameters of the proposed converter

\begin{tabular}{|c|c|}
\hline Circuit components & Values \\
\hline Boost Inductor $\left(L_{b}\right)$ & $90 \mu \mathrm{H}$ \\
\hline Inductor $\left(L_{1}\right)$ & $80 \mathrm{mH}$ \\
\hline Inductor $\left(L_{2}\right)$ & $80 \mathrm{mH}$ \\
\hline Filter Capacitor $\left(C_{1}\right)$ & $1 \mu \mathrm{F}$ \\
\hline Capacitor $\left(C_{2}\right)$ & $0.1 \mu \mathrm{F}$ \\
\hline Capacitor $\left(C_{3}\right)$ & $13 \mu \mathrm{F}$ \\
\hline Capacitor $\left(C_{4}\right)$ & $13 \mu \mathrm{F}$ \\
\hline Load Resistor $\left(R_{L}\right)$ & $10 \mathrm{k} \Omega$ \\
\hline
\end{tabular}

Table II: Specifications of the proposed converter

\begin{tabular}{|c|c|}
\hline Specifications & Values \\
\hline Input voltage & $80 \mathrm{~V}(\mathrm{rms})$ \\
\hline Output voltage & $800 \mathrm{~V}(\mathrm{DC})$ \\
\hline Switching frequency & $50 \mathrm{kHz}$ \\
\hline Maximum output power & $500 \mathrm{~W}$ \\
\hline
\end{tabular}

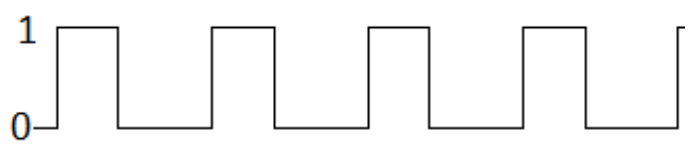

(a)

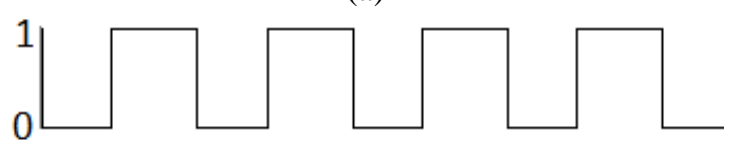

(b)

Fig. 3(a) and (b) Gating pulses to the switches $S_{1}$ and $S_{2}$

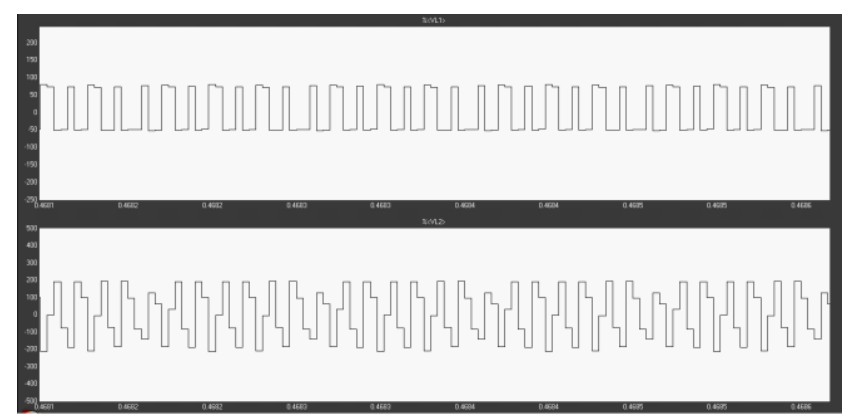

Fig. 4 Waveforms of voltages across $\mathrm{L}_{1}$ and $\mathrm{L}_{2}$

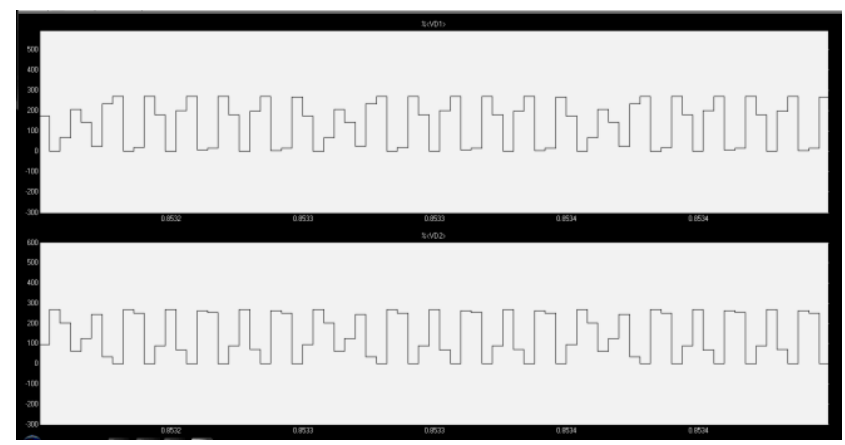

Fig. 5 Waveforms of voltages across $\mathrm{D}_{1}$ and $\mathrm{D}_{2}$

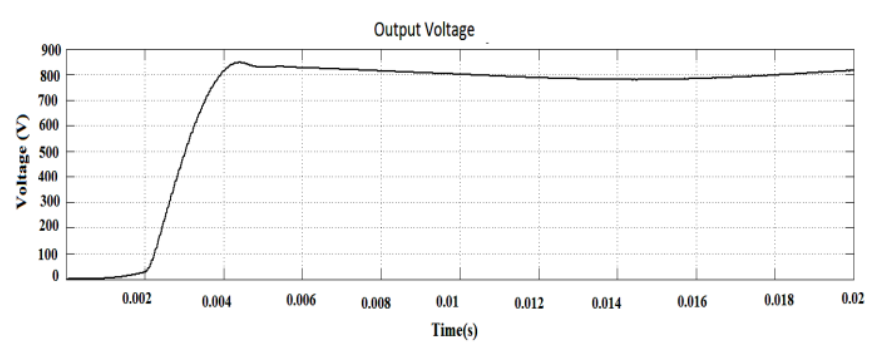

Fig. 6 Waveform of output voltage across the load $\mathrm{R}_{\mathrm{L}}$ 


\section{International Journal of Engineering Applied Sciences and Technology, 2019 \\ Vol. 4, Issue 8, ISSN No. 2455-2143, Pages 160-164 \\ Published Online December 2019 in IJEAST (http://www.ijeast.com)}

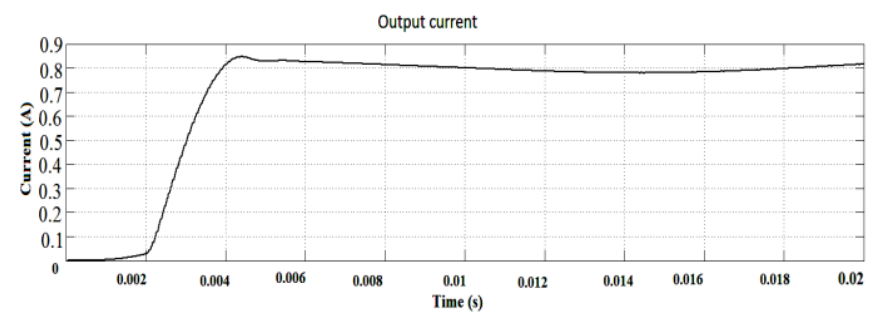

Fig. 7 Waveform of current through the load $\mathrm{R}_{\mathrm{L}}$

In order to regulate the output voltage of the proposed converter, a Proportional + Integral (PI) controller with properly tuned controller parameters (Proportional gain $K_{P}=$ 0.0012 , Integral gain $K_{I}=0.97$ ) has been introduced. The waveforms of voltages across the inductors $L_{1}$ and $L_{2}$ are shown in Fig. 4. The waveforms of voltages across the diodes $\mathrm{D}_{1}$ and $\mathrm{D}_{2}$ are shown in Fig. 5. An AC input voltage of $80 \mathrm{~V}$ (rms) is given as input to the rectifier. The DC output voltage at the end of the second stage is around $800 \mathrm{~V}$. The output voltage is almost 10 times the $\mathrm{AC}$ input voltage. The output current is of the order of $0.8 \mathrm{~A}$. The voltage and current waveforms pertaining to the load are shown in Figs. 6 and 7.

\section{PRototype Model OF CONVERTER}

A prototype model of the proposed two-stage DC-DC converter has been developed to provide an output voltage of $400 \mathrm{~V}$ (DC) only when the source voltage is in the range of 80 $\mathrm{V}$ (DC) at the output of rectifier. The boost stage is not used in the prototype model. The experimental setup for the prototype model is shown in Fig. 8. The duty ratio ' $D$ ' for the main switches $S_{1}$ and $S_{2}$ is taken as 0.7 . The components of the prototype model of the converter are listed as shown in Table III. The gating signals are given to the Power MOSFETs as shown in Fig. 9 (a) and (b) to turn them ON. The input voltage to the converter is set at $85 \mathrm{~V}$ (DC) as shown by the multimeter reading in Fig. 8. The output voltage at the end of the second stage is maintained approximately at $401 \mathrm{~V}$ (DC) as measured by the multimeter in Fig. 8 .

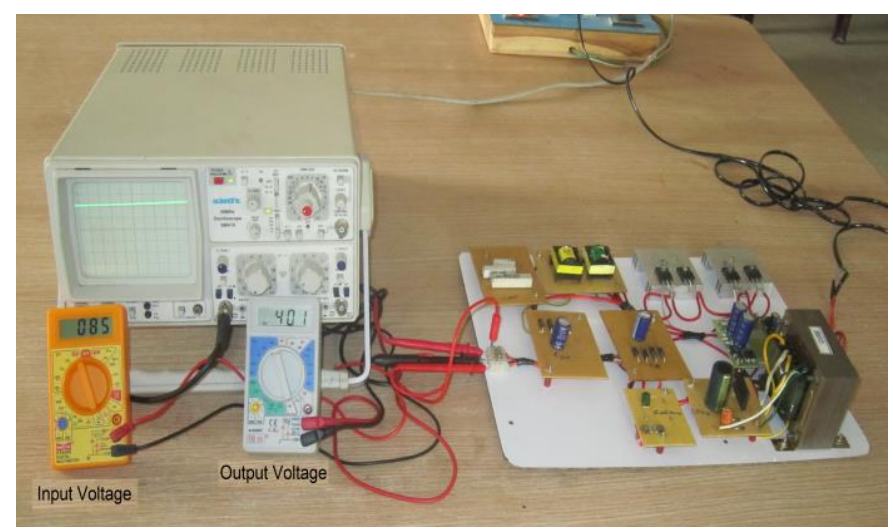

Fig. 8 Prototype model of the converter

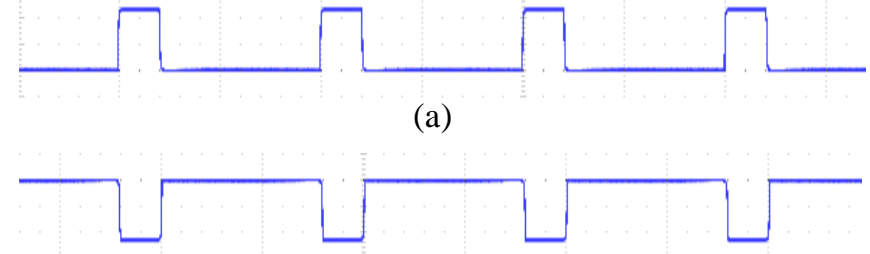

(b)

Fig. 9(a) and (b) Gating pulses to the Power MOSFETs $\left(\mathrm{S}_{1}\right.$ and $\left.\mathrm{S}_{2}\right)$

Table III: Components of prototype DC-DC converter model

\begin{tabular}{|c|c|c|}
\hline Circuit components & Description & Type \\
\hline $\mathrm{S}_{1}, \mathrm{~S}_{2}, \mathrm{~S}_{\mathrm{b}}$ & Power MOSFETS & $\begin{array}{c}\text { IRF150N, } \\
200 \mathrm{~V}, 30 \mathrm{~A}\end{array}$ \\
\hline $\mathrm{D}_{1}, \mathrm{D}_{2}, \mathrm{D}_{\mathrm{br}}$ & Diodes & $\begin{array}{c}\text { IN5408, } \\
1000 \mathrm{~V}, 3 \mathrm{~A}\end{array}$ \\
\hline$L_{1}$ & Filter Inductor & $50 \mu \mathrm{H}$ \\
\hline$L_{2}$ & Auxiliary Inductor & $7 \mu \mathrm{H}$ \\
\hline$C_{1}$ & Filter Capacitor & $1 \mu \mathrm{F}$ \\
\hline$C_{2}=C_{3}=C_{4}$ & Capacitor & $33 \mu \mathrm{F}$ \\
\hline$f_{s}$ & Switching frequency & $60 \mathrm{kHz}$ \\
\hline$R_{L}$ & Load Resistor & $5 \mathrm{k} \Omega$ \\
\hline$P_{L}$ & Output power & $100 \mathrm{~W}$ \\
\hline$I_{L}$ & Output current & $0.5 \mathrm{~A}$ \\
\hline
\end{tabular}

\section{CONCLUSION}

In this paper, the closed-loop implementation of a rectifier-fed non-isolated step-up DC-DC converter with PI controller is analyzed. The time-domain simulations are carried out in Matlab/Simulink environment to validate the performance of the proposed converter. The results demonstrate that the proposed converter configuration has the capability to produce an output voltage which is almost ten times the input $\mathrm{AC}$ voltage. Hence, the proposed converter topology can improve the voltage gain of the system. In the proposed converter configuration, the switches are turned on and off by the conventional Pulse Width Modulation technique. In order to regulate the output voltage, a properly tuned PI controller has been introduced in this work. A prototype model is also developed to validate the effectiveness of the converter.

\section{REFERENCES}

[1] Zhu J. Y. and Lehman B. (2005), “Control loop design for two-stage DC-DC converters with low voltage/high current output", IEEE Transactions on Power Electronics, Vol. 20, No. 1, pp. 44-55. 


\section{International Journal of Engineering Applied Sciences and Technology, 2019 \\ Vol. 4, Issue 8, ISSN No. 2455-2143, Pages 160-164 \\ Published Online December 2019 in IJEAST (http://www.ijeast.com)}

[2] Abe S., Yamamoto J., Zaitsu T., and Ninomiya T. (2003), "Extension of bandwidth of two-stage DC-DC converter with low-voltage/high-current output", Proceedings of IEEE 34th Annual Conference on Power Electronics Specialist, Vol. 4, pp. 1593-1598.

[3] Dixon L.H., Jr. (1990), "High power factor preregulators for off-line power supplies", Unitrode Switching Regulator Power Supply Design Seminar Manual, Paper 12, SEM-700.

[4] Zhang J., Jovanovic M.M., and Lee F.C. (1999), "Comparison between CCM single-stage and two-stage boost PFC converters", Proceedings of 14th Annual Applied Power Electronics Conference and Exposition.

[5] Piao C., Qiao H., and Teng C. (2012), "Digital control algorithm for two-stage DC-DC converters", Energy Procedia, Vol. 16, pp. 265-271.

[6] Wen P., Hu C., Yang H., Zhang L., Deng C., Li Y., and $\mathrm{Xu}$ D. (2014), "A two-stage DC/DC converter with wide input range for EV", Proceedings of International Power Electronics Conference.

[7] Forouzesh M., Siwakoti Y.P., Gorji S.A., Blaabjerg F., and Lehman B. (2017), "Step-up DC-DC converters: A comprehensive review of voltage-boosting techniques, topologies, and applications", IEEE Transactions on Power Electronics, Vol. 32, No. 12, pp. 9143-9178.

[8] Alzahrani and Ahmad (2018), "Advanced topologies of high-voltage-gain DC-DC boost converters for renewable energy applications", Doctoral Dissertations-Missouri University of Science and Technology.

[9] Sri Sivani L., Nagi Reddy B., Subba Rao K., and Pandian A. (2019), "A new single switch AC/DC converter with extended voltage conversion ratio for SMPS applications", International Journal of Innovative Technology and Exploring Engineering, Vol. 8, No. 3, pp. 68-72.

[10] Li T. and Parsa L. (2018), "Design, control, and analysis of a fault-tolerant soft-switching DC-DC converter for high-power high-voltage applications", IEEE Transactions on Power Electronics, Vol. 33, No. 2, pp. 1094-1104.

[11] Singh S., Bhuvaneswari G., and Bhim Singh (2012), "Power quality improvement in switched mode power supplies using two-stage DC-DC converter", International Journal of Engineering, Science and Technology, Vol. 4, No. 1, pp. 55-64.

[12] Park S. and Choi S. (2010), "Soft-switched CCM boost converters with high voltage gain for high-power applications", IEEE Transactions on Power Electronics, Vol. 25, No. 5, pp. 1211-1217.

[13] Kim C., Moon G., and Han S. (2007), "Voltage doubler rectified boost-integrated half bridge (VDRBHB) converter for digital car audio amplifiers", IEEE
Transactions on Power Electronics, Vol. 22, No. 6, pp. 2321-2330.

[14] Alzahrani A., Ferdowsi M., and Shamsi P. (2019), "Highvoltage-gain DC-DC step-up converter with Bifold Dickson voltage multiplier cells", IEEE Transactions on Power Electronics, Vol. 34, No. 10, pp. 9732-9742.

[15] Abdel-Rahman S., Stuckler F., and Siu K. (2016), "PFC boost converter design guide", Infineon Application Note, Revision 1.1. 